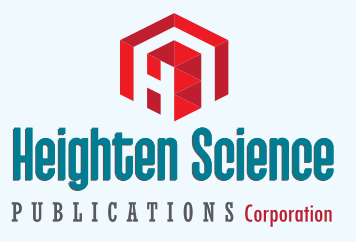

ISSN

2573-6264

\title{
Functional Electrical Stimulation (FES): Clinical successes and failures to date
}

\author{
Gad Alon* \\ Associate Professor, Emeritus, University of Maryland, School of Medicine, Department of \\ Physical Therapy \& Rehabilitation Science, Baltimore, MD 21201, USA
}

\begin{abstract}
*Address for Correspondence: Gad Alon, PhD, PT, Associate Professor, Emeritus, University of Maryland, School of Medicine, Department of Physical Therapy \& Rehabilitation Science, Baltimore, MD 21201, USA, Email:

galon@som.umaryland.edu
\end{abstract}

Submitted: 26 October 2018

Approved: 01 November 2018

Published: 02 November 2018

Copyright: @ 2018 Alon G. This is an open access article distributed under the Creative Commons Attribution License, which permits unrestricted use, distribution, and reproduction in any medium, provided the original work is properly cited

Check for updates

\section{Abstract}

Non-invasive electrical stimulation in the form of neuromuscular electrical stimulation (NMES) and functional electrical stimulation (FES) has been documented as an optional assessment and treatment technology for decades. In contrast, translation of the robust clinical evidence supporting the effectiveness of FES' enhancement of muscle force generation and adding to the recovery of motor control following damage to the brain appears limited. Furthermore, enabling many patients to regain locomotion ability though utilization of FES as a standard care option in rehabilitation medicine remains unmet. This perspective evolved over years of collaborative experience in clinical research, teaching, and patient care having a common goal of advancing patients' rehabilitation outcomes. The clinical successes are supported by repeated evidence of FES utilization across the life span, from toddlers to elders, from hospitals' critical care units to the home environment. The utilization include managing multiple deficits associated with the musculo-skeletal, neurological, cardio-pulmonary, or peripheral vascular systems. These successes were achieved in no small part because of the technological advancement leading to today's wearable wireless FES systems that are being used throughout the continuum of rehabilitation care. However, failures to benefit from FES utilization are likewise numerous, collectively depriving most patients from using the technology to maximize their rehabilitation gains. The most critical failures are both clinical and technological. Whereas numerous barriers to NMES and FES utilization have been published, the focus of this perspective is on barriers not considered to date.

Functional electrical stimulation (FES) is a well-established technology aimed to enhance recovery after damage to the brain, spinal cord, musculoskeletal, and peripheral vascular systems. FES is currently utilized in clinical practice around the world and has been undergoing refinements over the years taking advantage of the fast-moving evolution in electronic hardware and software, as well as the remarkable proliferation of biocompatible wearable materials. Recent clinical deployment of wearable wireless FES systems marked a turning point toward the goal of establishing FES as a treatment option throughout the continuum of care in rehabilitation medicine. Typical FES is comprised of a stimulator delivering via non-invasive surface electrodes, electric pulses of very short duration, typically lasting 10-500 $\mu \mathrm{sec}$. These pulses excite peripheral sensory and motor nerves thereby causing contraction of skeletal muscles while concurrently modulate neural connectivity throughout the central and peripheral neural networks [1-4]. In numerous peer-reviewed scientific clinical publications, these stimulators are termed neuromuscular electrical stimulators (NMES). When these stimulators are applied during the performance of specific tasks or during daily functions, the term FES rather than NMES describes more appropriately the utilization of these stimulators. A detailed discussion of utilizing FES in clinical practice has been published by Alon elsewhere [5].

The mechanisms that govern the application of noninvasive FES/NMES have been delineated and clearly described in published clinical trials. A cascade of events recognized at the molecular level include up-regulation of IGF-1, modulation of MuRF- 
1 (a muscle-specific atrophy-related gene), and up-regulation of relevant markers of differentiating satellite cells leading to extracellular matrix remodeling, which may restore the mechanical forces of the trained skeletal muscle, maintain satellite cell function, and reduce fibrosis [6,7]. Other studies demonstrated that electrically induced contractions significantly increase total RNA content and reduce protein degradation [8], increase body cell mass, attenuate reduction of intracellular water, alleviate arterial hemodynamic disturbance [9], reduce tumor necrosis factor (TNFalpha) that is associated with systemic inflammation, and increase beta-endorphin levels[10]. The enhancement of these molecular and cellular metabolic events are all markers supporting long-established clinical data demonstrating that using FES is likely to result in significant muscle strength gains whether the strength deficits were a result of damage to the musculoskeletal, neurological or cardiovascular-pulmonary systems[11-15]. Moreover, FES activation of skeletal muscles has been shown to enhance arterial, venous and lymphatic flow [16-19], while concurrently transmitting multimodal afferent signals to multiple sites within the brain's regions of interest (ROI) [1-4]. Collectively, the science supporting the mechanisms and clinical benefits of utilizing FES in the management of physical and functional deficits is robust, yet FES utilization as a common treatment option in daily clinical practice is limited at best.

\section{FES as a clinical training tool}

Traditionally, FES has been utilized predominantly to promote lower and upper extremity functions $[11,12,16,20-24]$ and to a lesser extent to activate the abdominal and torso muscles $[8,25,26]$. For many years, FES systems included a battery-powered stimulator connected with lead wires to the stimulating electrodes and a wired external trigger to synchronize muscle contraction with the functional activity $[27,28]$. Owing to advancements in hardware, software, and biocompatible materials, patients and clinicians begun utilizing what is generically referred to as wearable, wireless FES systems $[22,29$ 31]. These latest systems are self-administered and controlled by each patient. Having low profile, they can be worn comfortably under clothing while functioning in the home and the community. The utility of FES can be categorized as either FES-dependent, which enables the patient to perform specific tasks or functions that they cannot perform as well without FES, or FES-independent (re-learned) where the patient is using the FES for a finite period to minimize impairments and dysfunctions while re-learning how to perform eventually the specific tasks and functions without FES. Initially, when patients begin training with FES, they all depend on the FES to walk better or make better use of the paretic extremity [32,33]. Over time, some patients should reach the goal of independence and no longer need the FES while others will continue to depend on the FES for the foreseeable future. Failing to reach independence of FES is most likely an indication that the connectivity of the sensory-motor networks within the brain, the spinal cord or both, were not re-modeled sufficiently to the pre-damage connectivity.

The failure to recover pre-damage connectivity using FES is likely to originate in part from intrinsic, potentially non-reversal damage to the central and peripheral body's systems. These damages are not considered in this perspective nor is the uncounted number of patients who for various reasons are not candidates for FES intervention. In a recent paper, Auchstaetter and colleagues identified a number of barriers to the utilization of FES by physical therapists in clinical practice [34]. These barriers as well as practical issues including patients' tolerance, or reimbursement challenges are likewise not the focus of this paper. This perspective focus on patients who should, but are not screened as potential candidates to benefit from training with FES. A number of shortcomings of current methodologies are likely to impact adversely these patients. For example, a typical consort diagram from a multi-center randomized clinical trial indicated that only about $10 \%$ of stroke survivors met inclusion criteria [35,36]. As a result $90 \%$ of stroke survivors are not likely to benefit from the study's published results. Similarly, the method of classifying responders and non-responders should be 
challenged. The intra and inter patients' variability responding to physical rehabilitation interventions including FES is well known [37]. Accordingly, changing the focus from group response to each individual patient's needs and perception of benefits, should increase considerably the number of beneficiaries from FES training [38]. As written elsewhere in details [5], this author proposal to clinicians and researchers is to adopt a personalized clinical approach. The approach must be predicated on the ability to identify each patient's physical functional deficits, and utilize FES to restore in part or in full her/his functional ability. As stated above the multitude of other documented barriers are outside the scope of this perspective.

Whereas advanced FES systems are wearable, wireless and can be applied independently by the user, they all provide a predetermined stimulation intensity during ambulation or upper extremity use $[24,29,30,32,33]$. These open loop technologies induce strong muscle contraction regardless of how much contraction the patient can generate cortically or subcortically-meaning independent of FES. This may explain why most patients remain FES dependent even after months and years of use. A likely pathway to overcome such shortcoming and achieve functional use of the upper extremity or locomotion and no longer depend on FES, or to maximize FES-dependent functionality, is to develop a closed-loop system. Such system uses iterative algorithms (repetitions of sequence of steps) to control the desired level of the electrically induced contraction of the target muscles [20,39-41]. Common requirements to formulate iterative algorisms is to construct the desired movement pattern that characterize walking or non-walking daily functions such as standing up and sitting down. Algorisms are also being developed for reaching, grasping, moving and releasing objects with the upper extremity. Furthermore, the guiding principle to improve recovery of connectivity within the brain's motor network thereby enabling control of activities of daily living (ADL), include application of appropriate closed-loop control. Having such control enables each patient to use her/his internal sensory-motor control system and add FES only to complete the portion of the motion the internal control failed to achieve.

Iterative algorisms depend on input signals typically obtained using non-invasive electromyography (EMG) or motion sensors [42-46]. Less common is the use of electroencephalography (EEG) derived signals to control the FES $[47,48]$. Both EMG and motion sensing inputs can be obtained from the paretic limb or remotely from non-paretic locations. Advancement in EMG processing, specifically evoked EMG recordings and miniaturization of necessary hardware meet the demand for combining it with FES as a wireless wearable system offering continuous closed-loop control of the FES induced contraction $[43,49]$. Few researchers are "bridging" wirelessly the EMG signals from non-paretic muscles to remotely increase or decrease the electrically induced contraction [42]. The primary limitation of using EMG or EEG-driven control signals include the addition of hardware circuitry, size, battery drain, and cost of the system. Using the nonparetic to control the paretic upper extremity an approach offered by Wang et al. [42], or Knutson and colleagues [21], limit the nonparetic limb from participating in functional ADL because of the continuous need to control proportional opening, closing, and moving the paretic limb.

Inertial measurement units (IMU) are motion sensors that may prove the preferred option for close-loop control of FES [41,50,51], these motion sensors are miniature in size, can be incorporated within the same electronic circuit of the FES [16], can wirelessly communicate with other sensors of the system, and consume very little power. Using two or more motion sensors can provide continuous kinematic data, specifically of individual joint range of motion (ROM) during the performance of specific task or daily function $[41,52,53]$. The iterative approaches to manage the motion sensors data can be used to control the intensity of stimulation needed to complete the task [44,54]. Unfortunately, the above referenced studies are conducted in laboratory settings and their utility as a commercial product in clinical practice is 
yet to be tested. Commercially available systems use the motion sensors as a trigger (on-off) to activate the FES at the correct timing of the task or function, but not to control the desired intensity of stimulation $[22,24,29,30]$. Such limitation may explain why most patients continue to be FES dependent despite several years of daily use.

Other limitations of the latest wearable, wireless FES systems include the low resolution of induced muscle contraction, the absence of verifiable algorithms to expand the utility of FES to train non-walking daily functions including training to stand up and sit down independently. The limited availability of clinically valued coupling of FES with other rehabilitation technologies such as EEG controlled FES $[55,56]$, or wearable robots and virtual reality systems [57], is also recognized in the literature [36]. Attempts to improve the resolution of FES induced muscle contraction by using multiplexers and arrays of small electrodes $[39,58]$ or manipulation of pulse parameters [1] have yielded some interesting discoveries and electronic innovations. But these research efforts have also failed so far to become a viable commercial product in rehabilitation medicine. Collectively, the main challenge researchers are facing is to design, construct, fabricate, and bring to the market reliable, cost-effective, and durable closed-loop controlled wearable wireless FES systems.

\section{References}

1. Wegrzyk J, Ranjeva JP, Fouré A, Kavounoudias A, Vilmen C, et al. Specific brain activation patterns associated with two neuromuscular electrical stimulation protocols. Sci Rep. 2017; 7: 27-42. Ref.: https://goo.gl/pvyyB2

2. Gandolla M, Ward NS, Molteni F, Guanziroli E, Ferrigno G, et al. The Neural Correlates of Long-Term Carryover following Functional Electrical Stimulation for Stroke. Neural Plast. 2016; 2016: 4192718. Ref.: https://goo.gl/t7fX4q

3. Sasaki K, Matsunaga T, Tomite T, Yoshikawa T, Shimada Y, et al. Effect of electrical stimulation therapy on upper extremity functional recovery and cerebral cortical changes in patients with chronic hemiplegia. Biomed Res. 2012; 33: 89-96. Ref.: https://goo.gl/uoSX3h

4. Smith GV, Alon G, Roys SR, Gullapalli RP. Functional MRI determination of a dose-response relationship to lower extremity neuromuscular electrical stimulation in healthy subjects. Exp Brain Res. 2003; 150: 33-39. Ref.: https://goo.gl/5Qbt5X

5. Alon G. Functional Electrical Stimulation (FES): Transforming Clinical Trials to Neuro-Rehabilitation Clinical Practice- A Forward Perspective. Journal of Novel Physiotherapies, 2013; 3: Ref.: https://goo.gl/1MDzkf

6. Di Filippo ES, Mancinelli R, Marrone M, Doria C, Verratti V, et al. Neuromuscular electrical stimulation improves skeletal muscle regeneration through satellite cell fusion with myofibers in healthy elderly subjects. J Appl Physiol. (1985); 2017: 123: 501-512. Ref.: https://goo.gl/FnFqr3

7. Kern H, Barberi L, Löfler S, Sbardella S, Burggraf S. et al. Electrical stimulation counteracts muscle decline in seniors. Front Aging Neurosci. 2014; 6: 189. Ref.: https://goo.gl/1C1iki

8. Strasser EM, Stättner S, Karner J, Klimpfinger M, Freynhofer M, et al. Neuromuscular electrical stimulation reduces skeletal muscle protein degradation and stimulates insulin-like growth factors in an age- and current-dependent manner: a randomized, controlled clinical trial in major abdominal surgical patients. Ann Surg. 2009; 249: 738-743. Ref.: https://goo.gl/jGESDw

9. Huang SC, Wong AM, Chuang YF, Liu YC, Tsai WL, et al. Effects of neuromuscular electrical stimulation on arterial hemodynamic properties and body composition in paretic upper extremities of patients with subacute stroke. Biomed J. 2014; 37: 205-210. Ref.: https://goo.gl/qrbCW8

10. Vieira PJ, Chiappa AM, Cipriano G Jr, Umpierre D, Arena R, et al. Neuromuscular electrical stimulation improves clinical and physiological function in COPD patients. Respir Med. 2014; 108: 609-620. Ref.: https://goo.gl/T9zE9y

11. Yoshida Y, Ikuno K, Shomoto K. Comparison of the effect of sensory-level and conventional motorlevel neuromuscular electrical stimulation on quadriceps strength after total knee arthroplasty: a prospective randomized single-blind trial. Arch Phys Med Rehabil. 2017; 98: 2364-2370. Ref.: https://goo.gl/qKnSyj

12. Matsuse H, Hashida R, Takano $\mathrm{Y}$, Omoto $M$, Nago $T$, et al. Walking Exercise Simultaneously Combined With Neuromuscular Electrical Stimulation of Antagonists Resistance Improved Muscle Strength, Physical Function, and Knee Pain in Symptomatic Knee Osteoarthritis: A Single-Arm Study. J Strength Cond Res. 2017; 31: 171-180. Ref.: https://goo.gl/UbLNDy 
13. Brüggemann AK, Mello CL, Dal Pont T, Hizume Kunzler D, Martins DF, et al. Effects of Neuromuscular Electrical Stimulation during Hemodialysis on Peripheral Muscle Strength and Exercise Capacity: A Randomized Clinical Trial. Arch Phys Med Rehabil, 2017; 98: 822-831 e1. Ref.: https://goo.gl/npkC4h

14. Grosset JF, Canon F, Pérot C, Lambertz D. Changes in contractile and elastic properties of the triceps surae muscle induced by neuromuscular electrical stimulation training. Eur J Appl Physiol. 2014; 114: 1403-1411. Ref.: https://goo.gl/NDGdNx

15. Ambrosini E, Ferrante S, Pedrocchi A, Ferrigno G, Molteni F. Cycling induced by electrical stimulation improves motor recovery in postacute hemiparetic patients: a randomized controlled trial. Stroke, 2011; 42: 1068-1073. Ref.: https://goo.gl/vW2ibP

16. Embrey DG, Alon G, Brandsma BA, Vladimir F, Silva A, et al. Functional electrical stimulation improves quality of life by reducing intermittent claudication. Int J Cardiol, 2017; 243: 454-459. Ref.: https://goo.gl/wmU6Lq

17. Williams KJ, Moore HM, Davies AH. Haemodynamic changes with the use of neuromuscular electrical stimulation compared to intermittent pneumatic compression. Phlebology. 2015; 30: 365372. Ref.: https://goo.gl/e77JCG

18. Mifsud M, Cassar K. The Use of Transcutaneous Electrical Stimulation of the Calf in Patients Undergoing Infrainguinal Bypass Surgery. Ann Vasc Surg. 2015; 29: 1524-1532. Ref.: https://goo.gl/CRmxHk

19. Tucker AT, Maass A, Bain DS, Chen LH, Azzam M, et al. Augmentation of venous, arterial and microvascular blood supply in the leg by isometric neuromuscular stimulation via the peroneal nerve. Int J Angiol. 2010; 19: e31-37. Ref.: https://goo.gl/VkWUVb

20. Sampson P, Freeman C, Coote S, Demain S, Feys $P$, et al. Using Functional Electrical Stimulation Mediated by Iterative Learning Control and Robotics to Improve Arm Movement for People with Multiple Sclerosis. IEEE Trans Neural Syst Rehabil Eng. 2016; 24: 235-248. Ref.: https://goo.gl/74xRX2

21. Knutson JS, Gunzler DD, Wilson RD, Chae J. Contralaterally Controlled Functional Electrical Stimulation Improves Hand Dexterity in Chronic Hemiparesis: A Randomized Trial. Stroke, 2016; 47: 2596-2602. Ref.: https://goo.gl/ctDk7D

22. Springer $S$, Khamis $S$, Laufer $Y$. Improved ankle and knee control with a dual-channel functional electrical stimulation system in chronic hemiplegia. A case report. Eur J Phys Rehabil Med. 2014; 50 189-195. Ref.: https://goo.gl/ojVNwV

23. Pool D, Blackmore AM, Bear N, Valentine J. Effects of short-term daily community walk aide use on children with unilateral spastic cerebral palsy. Pediatr Phys Ther. 2014; 26: 308-317. Ref.: https://goo.gl/bTWPKJ

24. O'Dell MW, Dunning K, Kluding P, Wu SS, Feld J, et al. Response and prediction of improvement in gait speed from functional electrical stimulation in persons with poststroke drop foot. PM R. 2014; 6: 587-601. Ref.: https://goo.gl/6pyZxQ

25. Kamel DM, Yousif AM. Neuromuscular Electrical Stimulation and Strength Recovery of Postnatal Diastasis Recti Abdominis Muscles. Ann Rehabil Med. 2017; 41: 465-474. Ref.: https://goo.gl/QsDds4

26. Porcari JP, Miller J, Cornwell K, Foster C, Gibson M, et al. The effects of neuromuscular electrical stimulation training on abdominal strength, endurance, and selected anthropometric measures. $\mathrm{J}$ Sports Sci Med. 2005; 4: 66-75. Ref.: https://goo.gl/knwCPu

27. Taylor $P$, Humphreys $L$, Swain I. The long-term cost-effectiveness of the use of Functional Electrical Stimulation for the correction of dropped foot due to upper motor neuron lesion. J Rehabil Med. 2013; 45: 154-160. Ref.: https://goo.gl/4m73Me

28. Alon G, Embrey DG, Brandsma BA, Stonestreet J. Comparing four electrical stimulators with different pulses properties and their effect on the discomfort and elicited Dorsiflexion. International J Physiotherapy Res. 2013; 1: 122-129. Ref.: https://goo.gl/3Juzv6

29. Springer $S$, Vatine JJ, Wolf A, Laufer $Y$. The effects of dual-channel functional electrical stimulation on stance phase sagittal kinematics in patients with hemiparesis. J Electromyogr Kinesiol, 2013; 23: 476-482. Ref.: https://goo.gl/2s3Ddc

30. Kluding PM, Dunning K, O'Dell MW, Wu SS, Ginosian J, et al. Foot drop stimulation versus ankle foot orthosis after stroke: 30-week outcomes. Stroke. 2013; 44: 1660-1669. Ref.: https://goo.gl/pnPDvu

31. Springer $S$, Vatine JJ, Wolf A, Laufer $Y$. The effects of dual-channel functional electrical stimulation on stance phase sagittal kinematics in patients with hemiparesis. J Electromyogr Kinesiol. 2013; 23 476-482. Ref.: https://goo.gl/AyoGMq

32. Alon G, Levitt AF, McCarthy PA. Functional electrical stimulation (FES) may modify the poor 
prognosis of stroke survivors with severe motor loss of the upper extremity: a preliminary study. Am J Phys Med Rehabil. 2008; 87: 627-636. Ref.: https://goo.gl/34BWwZ

33. Alon G, Levitt AF, McCarthy PA. Functional electrical stimulation enhancement of upper extremity functional recovery during stroke rehabilitation: a pilot study. Neurorehabil Neural Repair. 2007; 21: 207-215. Ref.: https://goo.gl/jD2aog

34. Auchstaetter N, Luc J, Lukye S, Lynd K, Schemenauer S, et al. Physical Therapists' Use of Functional Electrical Stimulation for Clients With Stroke: Frequency, Barriers, and Facilitators. Phys Ther. 2016; 96: 995-1005. Ref.: https://goo.gl/Pvz8aJ

35. Fabbrini S, Casati G, Bonaiuti D. Is CIMT a rehabilitative practice for everyone? Predictive factors and feasibility. Eur J Phys Rehabil Med. 2014; 50: 505-514. Ref.: https://goo.gl/nhaHJn

36. Dobkin $\mathrm{BH}$. Confounders in rehabilitation trials of task-oriented training: lessons from the designs of the EXCITE and SCILT multicenter trials. Neurorehabil Neural Repair. 2007; 21: 3-13. Ref.: https://goo.gl/Rs5YpG

37. Raffin E, Hummel FC. Restoring Motor Functions after Stroke: Multiple Approaches and Opportunities. Neuroscientist. 2017; 24: 400-416. Ref.: https://goo.gl/Dccszc

38. van der Linden ML, Hooper JE, Cowan P, Weller BB, Mercer TH. Habitual functional electrical stimulation therapy improves gait kinematics and walking performance, but not patient-reported functional outcomes, of people with multiple sclerosis who present with foot-drop. PLoS One. 2014 9: e103368. https://goo.gl/9ijXVb

39. Kutlu M, Freeman CT, Hallewell E, Hughes AM, Laila DS. Upper-limb stroke rehabilitation using electrode-array based functional electrical stimulation with sensing and control innovations. Med Eng Phys. 2016; 38: 366-379. Ref.: https://goo.gl/H7on2Q

40. Freeman C, Exell T, Meadmore K, Hallewell E, Hughes AM. Computational models of upper-limb motion during functional reaching tasks for application in FES-based stroke rehabilitation. Biomed Tech (Berl). 2015; 60: 179-191. Ref.: https://goo.gl/zsEvKW

41. El-Gohary M, McNames J. Human Joint Angle Estimation with Inertial Sensors and Validation with a Robot Arm. IEEE Trans Biomed Eng. 2015; 62: 1759-1767. Ref.: https://goo.gl/f9E6fT

42. Wang HP, Bi ZY, Zhou Y, Zhou YX, Wang ZG, et al. Real-time and wearable functional electrical stimulation system for volitional hand motor function control using the electromyography bridge method. Neural Regen Res. 2017; 12: 133-142. Ref.: https://goo.gl/PkSefP

43. Li Z, Guiraud D, Andreu D, Gelis A, Fattal C, et al. Real-Time Closed-Loop Functional Electrical Stimulation Control of Muscle Activation with Evoked Electromyography Feedback for Spinal Cord Injured Patients. Int J Neural Syst. 2017; 1750063. Ref.: https://goo.gl/FnRhnV

44. Seel T, Werner C, Schauer T. The adaptive drop foot stimulator - Multivariable learning control of foot pitch and roll motion in paretic gait. Med Eng Phys. 2016; 38: 1205-1213. Ref.: https://goo.gl/iYKN65

45. Zhang Q, Hayashibe M, Azevedo-Coste C. Evoked electromyography-based closed-loop torque control in functional electrical stimulation. IEEE Trans Biomed Eng. 2013; 60: 2299-2307. Ref.: https://goo.gl/dvMwQW

46. Jovic J, Fraisse P, Coste CA, Bonnet V, Fattal C, et al. Improving valid and deficient body segment coordination to improve FES-assisted sit-to-stand in paraplegic subjects. IEEE Int Conf Rehabil Robot. 2011; 2011: 5975369. Ref.: https://goo.gl/1RT6aj

47. Ethier C, Acuna D, Solla SA, Miller LE. Adaptive neuron-to-EMG decoder training for FES neuroprostheses. J Neural Eng. 2016; 13: 046009. Ref.: https://goo.gl/qVvVds

48. Rocon E, Gallego JA, Barrios L, Victoria AR, Ibanez J, et al. Multimodal BCl-mediated FES suppression of pathological tremor. Conf Proc IEEE Eng Med Biol Soc. 2010; 2010: 3337-3340. Ref.: https://goo.gl/jWw7j7

49. Li Z, Guiraud D, Andreu D, Benoussaad M, Fattal C, et al. Real-time estimation of FES-induced joint torque with evoked EMG : Application to spinal cord injured patients. J Neuroeng Rehabil. 2016; 13 60. Ref.: https://goo.gl/KVt7Ak

50. Rueterbories J, Spaich EG, Andersen OK. Gait event detection for use in FES rehabilitation by radia and tangential foot accelerations. Med Eng Phys. 2014; 36: 502-508. Ref.: https://goo.gl/psSPX3

51. Mann G, Taylor P, Lane R. Accelerometer-triggered electrical stimulation for reach and grasp in chronic stroke patients: a pilot study. Neurorehabil Neural Repair. 2011; 25: 774-780. Ref.: https://goo.gl/7F1LZy 
52. Sun $M$, Kenney L, Smith $C$, Waring K, Luckie $H$, et al. A novel method of using accelerometry for upper limb FES control. Med Eng Phys. 2016; 38: 1244-1250. Ref.: https://goo.gl/WdK2ic

53. Ha KH, Murray SA, Goldfarb M. An Approach for the Cooperative Control of FES With a Powered Exoskeleton During Level Walking for Persons With Paraplegia. IEEE Trans Neural Syst Rehabil Eng. 2016; 24: 455-466. Ref.: https://goo.gl/vgHEa9

54. Salchow C, Valtin M, Seel T, TSchauer T. A New Semi-Automatic Approach to Find Suitable Virtual Electrodes in Arrays Using an Interpolation Strategy. Eur J Transl Myol. 2016; 26: 6029. Ref.: https://goo.gl/7JVufT

55. Biasiucci A, Leeb R, Iturrate I, Perdikis S, Al-Khodairy A, et al. Brain-actuated functional electrical stimulation elicits lasting arm motor recovery after stroke. Nat Commun. 2018; 9: 2421. Ref.: https://goo.gl/eVVzqr

56. Carda S, Biasiucci A, Maesani A, Ionta S, Moncharmont J, et al. Electrically Assisted Movement Therapy in Chronic Stroke Patients with Severe Upper Limb Paresis: A Pilot, Single-Blind, Randomized Crossover Study. Arch Phys Med Rehabil. 2017; 98: 1628-1635 e2. Ref.: https://goo.gl/iM2Nck

57. Anaya $F$, Thangavel $\mathrm{P}, \mathrm{Yu} \mathrm{H}$. Hybrid FES-robotic gait rehabilitation technologies: a review on mechanical design, actuation, and control strategies. International Journal of Intelligent Robotics and Applications. 2018; 2: 1-28. Ref.: https://goo.gl/Kd9dkH

58. Heller BW, Clarke AJ, Good TR, Healey TJ, Nair S, et al. Automated setup of functional electrical stimulation for drop foot using a novel 64 channel prototype stimulator and electrode array: results from a gait-lab based study. Med Eng Phys. 2013; 35: 74-81. Ref.: https://goo.gl/UYQshM 